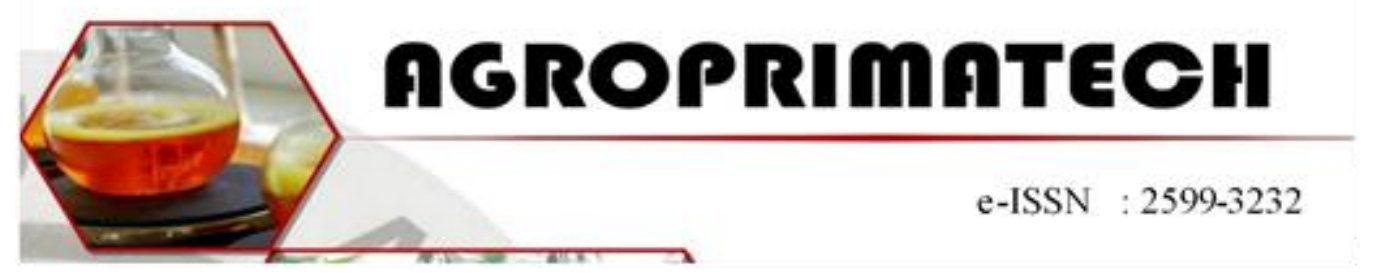

\title{
EFEKTIVITAS PELAYANAN PEMBUATAN PASPOR DENGAN MENGGUNAKAN SISTEM INFORMASI MANAJEMEN KEIMIGRASIAN (SIMKIM) TERHADAP KEPUASAN PELANGGAN DI KANTOR IMIGRASI KELAS II TANJUNG BALAI KARIMUN
}

\author{
ELA RIANA FARAMITA ${ }^{1}$, TRI MARDALENA ${ }^{2}$,NISHA DESFI ARIANTI ${ }^{2}$ \\ ${ }^{1}$ Mahasiswa Program Studi Manajemen Kepelabuhan dan Pelayaran, Fakultas Sains dan \\ Teknologi, Universitas Karimun, Karimun (29961) \\ ${ }^{2}$ Dosen Program Studi Manajemen Kepelabuhan dan Pelayaran, Fakultas Sains dan \\ Teknologi, Universitas Karimun, Karimun (29961) \\ Email : elariana2410@gmail.com
}

\begin{abstract}
ABSTRAK
Kelas II Tanjung Balai Karimun masih banyaknya mendapatkan keluhan dari masyarakat pengguna jasa keimigrasian khususnya pelayanan paspor. Penelitian ini bertujuan untuk mengetahui seberapa besar efektivitas pelayanan pembuatan paspor dengan menggunakan Sistem Informasi Manajemen Keimigrasian (SIMKIM) Terhadap Kepuasan Pelanggan di Kantor Imigrasi Kelas II Tanjung Balai Karimun. Teori yang digunakan adalah teori efektivitas menurut Hasibuan dengan indikator efektivitas yaitu produktivitas, efisiensi, adaptasi, pengembangan dan kepuasan. Metode penelitian yang digunakan adalah kuantitatif deskriptif. Sampel yang diambil sebanyak 150 orang dengan taraf kesalahan $5 \%$ dan menggunakan teknik purposive sampling. Teknik pengumpulan data yaitu kuesioner, studi dokumentasi, studi kepustakaan dan observasi. Dari hasil penelitian diperoleh efektivitas pelayanan pembuatan paspor dengan menggunakan Sistem Informasi Manajemen Keimigrasian (SIMKIM) Terhadap Kepuasan Pelanggan di Kantor Imigrasi Kelasll Tanjung Balai Karimun adalah $75,74 \%$ dari yang diharapkan atau dapat dikatakan baik karena mencapai angka diatas $70 \%$.
\end{abstract}

Kata Kunci: Efektivitas, Pelayanan, (SIMKIM), Kepuasan, Pelanggan

\section{PENDAHULUAN}

Direktorat Jendral Imigrasi yang berada dibawah naungan Kementerian Hukum dan Hak Asasi Manusia sebagai organisasi pemerintahan yang mempunyai tugas untuk mengatur arus perjalanan warga asing yang masuk ke wilayah Indonesia, sejak kedatangan dan setiap aktivitas mereka sampai kembali ke negaranya masing-masing. Menurut Undang - Undang No 6 Tahun 2011 tentang keimigrasian paspor $\mathrm{Rl}$ ialah surat perjalanan resmi yang diterbitkan pemerintah $\mathrm{Rl}$ kepada masyarakat Indonesia yang akan keluar negri dalam waktu yang sudah ditentukan. Paspor berisi data-data pemiliknya sesuai dengan ketentuan yang sudah berlaku. Dokumen tersebut harus dibawah WNI pada saat memasuki negara yang dituju dan ditunjukkan pada saat pemeriksaan sesuai juga dengan PP No. 31 tahun 2013 tentang paspor. 
Tingkat kebutuhan masyarakat luas akan paspor namun terkadang tidak sebanding dengan proses dalam pembuatan yang berbelit-belit dan biaya yang dikeluarkan dalam pembuatannya cukup tinggi. Belum lagi di beberapa wilayah di Indonesia dalam pembuatannya tak jarang harus menempuh jarak yang cukup jauh dikarenakan ketidaktersediannya di wilayah domisili tinggal, sehingga rasanya proses pembuatan paspor ini cukup lambat dan sangat sulit serta ketidakpastian waktu penyelesaiannya.

Instansi Pemerintahan berusaha meningkatkan kualitas pelayanan kepada masyarakat dengan mengikuti perkembangan teknologi informasi masakini, terutama dalam pelayanan pengurusan paspor. Dalam hal ini, Kantor Imigrasi Kelas II Tanjung Balai Karimun telah melakukan upaya dalam memberikan pelayanan tersebut berupa aplikasi online yaitu Sistem Informasi Manajemen Keimigrasian (SIMKIM).

\section{METODE PENELITIAN}

Penelitian ini dilaksanakan pada bulan Agustus 2019 yang bertempat di Kantor Imigrasi Kelas II Tanjung Balai Karimun, Jalan Jenderal A. Yani No. 105, Sungai Lakam, Kabupaten Karimun, Provinsi Kepulauan Riau. Jenis penelitian yang digunakan adalah penelitian kualitatif dengan pendekatan deskriptif. Dalam penelitian ini lebih ditekan pada kedalaman (kualitas) data bukan banyaknya (kuantitas) data. Secara jelas memberi gambaran mengenai masalahmasalah yang diteliti, menemukan jalan keluar masalah serta menjelaskan data yang ada secara sistematis.

Jumlah populasi dalam penelitian ini mencakup semua pelanggan yang menggunakan jasa pelayanan pembuatan paspor dengan menggunakan sistem informasi manajemen di Kantor Imigrasi Kelas II Tanjung Balai Karimun. Sampel penelitian ini berjumlah $50 \%$ dari $100 \%$ responden setiap hari Senin, Rabu dan

\begin{abstract}
Jum'at bagi pelanggan yang menggunakan jasa pelayanan pembuatan paspor dengan menggunakan sistem informasi manajamen keimigrasian di Kantor Imigrasi Kelas II Tanjung Balai Karimun.
\end{abstract}

\section{HASIL DAN PEMBAHASAN}

\subsection{Gambaran Umum Lokasi Penelitian}

Kantor Imigrasi Kelas II TPI Tanjung Balai Karimun didirikan pada tahun 1949 berdasarkan Lembaran Negara Republik Indonesia Staatsblad 1949, dengan mengalami beberapa kali perubahan, terakhir berdasarkan Surat Keputusan Menteri Hukum dan HAM RI Nomor 19 Tahun 2018 tentang Organisasi dan Tata Kerja Kantor Imigrasi. Sejak pertama berdiri bernama Kantor Jawatan Imigrasi, selanjutnya bernama Kantor Kelas I Tanjung Balai Karimun, kemudian diubah menjadi Kantor Imigrasi Kelas II Tanjung Balai Karimun dan saat ini bernama Kantor Imigrasi Kelas II TPI Tanjung Balai Karimun. Wilayah kerja Kantor Imigrasi Kelas II TPI Tanjung Balai Karimun meliputi seluruh wilayah Kabupaten Karimun yang terdiri dari 12 Kecamatan (29 Kelurahan dan 42 Desa) yaitu Kecamatan Moro, Kecamatan Durai, Kecamatan Kundur, Kecamatan Kundur Utara, Kecamatan Kundur Barat, Kecamatan Ungar, Kecamatan Belat, Kecamatan Karimun, Kecamatan Buru, Kecamatan Tebing, Kecamatan Meral dan Kecamatan Meral Barat.

\subsection{Karakteristik Responden}

Karakteristik responden digunakan untuk mengetahui keragaman dari responden berdasarkan jenis kelamin, usia dan pekerjaan. Hal tersebut diharapkan dapat memberikan gambaran yang cukup jelas mengenai kondisi dari responden dan kaitannya dengan masalah dan tujuan penelitian tersebut. Untuk lebih jelasnya dapat dilihat pada tabel berikut ini: 
Tabel 4.1 Karakeristik Responden berdasarkan Jenis Kelamin

\begin{tabular}{|c|c|c|c|}
\hline No & Jenis Kelamin & Jumlah & Persentase \\
\hline 1 & Perempuan & 76 & $50,6 \%$ \\
\hline 2 & Laki-laki & 74 & $49,3 \%$ \\
\hline \multicolumn{2}{|c|}{ Jumlah } & 150 orang & $100 \%$ \\
\hline
\end{tabular}

Sumber: Data Primer (2019)

Berdasarkan tabel 4.1 di atas maka dapat diketahui jumlah responden sebanyak 150 orang. Jumlah diatas menjelaskan bahwa yang menjadi responden penelitian di Kantor Imigrasi Kelas II Tanjung Balai Karimun lebih banyak didominasi oleh pemohon perempuan yaitu sebanyak 76 orang $(50,6 \%)$ dibandingkan dengan pemohon laki-laki yaitu sebanyak 74 orang $(49,3 \%)$. Hal tersebut dikarenakan pada saat penelitian, peneliti menemukan responden yang berjenis kelamin perempuan lebih banyak mengajukan permohonan paspor dengan tujuan untuk bekerja dan kepentingan diluar negri.

Tabel 4.2 Karakeristik Responden berdasarkan Usia

\begin{tabular}{|c|c|c|c|}
\hline No & Usia & Jumlah & Persentase \\
\hline 1 & $19-25$ Tahun & 74 & $49,3 \%$ \\
\hline 2 & $26-31$ Tahun & 32 & $21,3 \%$ \\
\hline 3 & $>32$ & 44 & $29,3 \%$ \\
\hline \multicolumn{2}{|c|}{ Jumlah } & 150 orang & $100 \%$ \\
\hline
\end{tabular}

Sumber: Data Primer (2019)

Berdasarkan tabel 4.2 diatas maka dapat diketahui bahwa para pemohon paspor (responden) dalam penelitian ini berdasarkan tingkat usianya didominasi oleh tingkat usia antara 19-25 tahun yaitu sebanyak 74 orang (49,3\%). Artinya dengan jumlah karakteristik usia diatas responden yang berusia 19- 25 tahun yang mendominasi menunjukan usia produktif belajar dan masa antusiasme dalam bekerja.

Tabel 4.3 Karakeristik Responden berdasarkan Bidang Kerja

\begin{tabular}{|c|c|c|c|}
\hline No & Usia & Jumlah & Persentase \\
\hline 1 & $19-25$ Tahun & 74 & $49,3 \%$ \\
\hline 2 & $26-31$ Tahun & 32 & $21,3 \%$ \\
\hline 3 & $>32$ & 44 & $29,3 \%$ \\
\hline \multicolumn{2}{|c|}{ Jumlah } & 150 orang & $100 \%$ \\
\hline
\end{tabular}

Sumber: Data Primer (2019)

\section{Berdasarkan}

karakteristik

responden sesuai bidang kerja pada tabel 4.3 diatasdidominasi Buruh 44 orang $(29,3 \%)$. Hal tersebut dikerenakan sebagian masayarakat Tanjung Balai Karimun khususnya pelanggan Kantor Imigrasi Kelas II Tanjung Balai Karimun banyak yang bekerja diluar negri.

\subsection{Tanggapan Responden}

\section{a. Efektivitas Pelayanan}

Berdasarkan Kriteria deskriptif persentase dari hasil penelitian peneliti di Kantor Imigrasi Kelas II Tanjung Balai
Karimun terhadap Responden/pelanggan dengan menyebarkan angket/kuesioner tertutup didapat Kriteria deskriptif persentase responden sebesar $77,4 \%$ untuk efektivitas pelayanan atau variabel $x$, hal ini menunjukan jawaban responden terhadap efektivitas pelayanan pembuatan paspor dengan menggunakan simkim berada dikategori baik.

Hal ini menunjukkan bahwa pelanggan yang berada di Kabupaten Karimun cukup puas dengan efektivitas pelayanan pembuatan paspor dengan menggunakan SIMKIM yang diberikan oleh 
Kantor Imigrasi Kelas II Tanjung Balai Karimun, walaupun masih terdapat beberapa kekurangan dari efektivitas pelayanan pembuatan paspor dengan menggunakan sistem informasi manajemen di Kantor Imigrasi Kelas II Tanjung Balai Karimun dari segi SDM maupun fasilitas yang ada di kantor.

Beberapa kekurangan tersebut ialah kurangnya sosialisasi terhadap masyarakat tentang aplikasi antrian online (APAPO) atau pelayanan terbaru yang telah dikeluarkan oleh Kantor Imigrasi Kelas II Tanjung Balai Karimun.

\section{b. Kepuasan Pelanggan}

Berdasarkan Kriteria deskriptif persentase dari hasil penelitian peneliti di Kantor Imigrasi Kelas II Tanjung Balai Karimun terhadap Responden/pelanggan dengan menyebarkan angket/kuesioner tertutup didapat Kriteria deskriptif responden sebesar 73,5\% untuk kepuasan pelanggan atau variabel y hal ini menunjukan jawaban responden/pelanggan terhadap kepuasan pelanggan dalam kategori baik. Dari hasil persentase $73,5 \%$ menunjukan bahwa pelanggan yang menggunakan jasa pembuatan paspor dengan menggunakan SIMKIM di Kantor Imigrasi Kelas II Tanjung Balai Karimun cukup puas atas pelayanan dari Kantor Imigrasi Kelas II Tanjung Balai Karimun, walaupun masih terdapat kekurangan yakni masih kurangnya keramahanan dari pegawai Kantor Imigrasi Kelas II Tanjung Balai Karimun dalam melayani pemohon.

\subsection{Uji Validitas}

Pengujian validitas dengan menggunakan Statistic Program Social Science (SPSS) versi 16.0, maka didapatkan hasil yaitu dari 20 butir pertanyaan keseluruhan pertanyaan dinyatakan valid sehingga dapat digunakan untuk dilanjutkan penelitian. Adapun kriteria item atau butir instrumen yang digunakan adalah apabila $r_{\text {hitung }}>$ $r_{\text {tabel, }}$ berarti item atau butir instrumen dinyatakan valid, dan jika $r_{\text {hitung }}<r_{\text {tabel, }}$, berarti item atau butir instrumen dinyatakan tidak valid. Berdasarkan hasil pengujian uji validitas diketahui bahwa semua instrumen adalah valid dibuktikan dari nilai $r_{\text {hitung }}>r_{\text {tabel }}, r_{\text {tabel }}$ pada taraf signifikasi 5 persen.

\subsection{Uji Reliabilitas}

Reliabilitas berfungsi untuk mengetahui tingkat kekonsistensian angket yang digunakan oleh peneliti sehingga angket tersebut dapat dihandalkan. Dasar pengambilan keputusan dalam uji reliabilitas adalah jika nilai Alpha Cronbach's lebih besar dari $r$ tabel maka item yang digunakan dinyatakan reliabel atau konsisten, sebaliknya jika Alpha Cronbach's lebih kecil dari $r$ tabel maka item yang digunakan dinyatakan tidak reliabel atau tidak konsisten.

\section{a. Uji Reliabilitas X}

Tabel 4.4 Reliabilitas Terhadap Efektivitas Pelayanan $(\mathrm{x})$

\begin{tabular}{|c|c|}
\hline Cronbach's Alpha & N of Items \\
\hline .721 & 10 \\
\hline
\end{tabular}

Berdasarkan hasil pengujian reliabilitas diatas, diketahui angka cronbach's alpha adalah sebesar 0,721. Jadi angka tersebut lebih besar dari nilai minimal cronbach's alpha 0,7. Oleh karena itu dapat disimpulkan bahwa instrument penelitian yang digunakan untuk mengukur variabel $(x)$ dapat dikatakan reliabel atau handal.

\section{b. Uji Reliabilitas Y}

Tabel 4.5 Reliabilitas Terhadap Kepuasan Pelanggan $(\mathrm{y})$

\begin{tabular}{|c|l|}
\hline Cronbach's Alpha & N of Items \\
\hline .671 & 10 \\
\hline
\end{tabular}

Berdasarkan hasil pengujian
reliabilitas diatas, diketahui angka
cronbach's alpha adalah sebesar 0,671 .
Jadi angka tersebut lebih besar dari nilai
minimal cronbach's alpha 0,7 . Oleh
karena itu dapat disimpulkan bahwa 
instrument penelitian yang digunakan untuk mengukur variabel (y) dapat dikatakan reliabel atau handal.

\subsection{Uji T-test}

Hasil Uji T-test dilakukan untuk menguji apakah ada pengaruh antara variabel $x$ dan variabel $y$. Hasil menunjukkan bahwa hipotesis yang diajukan oleh penulis dalam penelitian ini adalah sebagai berikut : "Efektivitas Pelayanan Pembuatan Paspor dengan Menggunakan Sistem Informasi Manajemen Keimigrasian (SIMKIM) Terhadap Kepuasan Pelanggan di Kantor Imigrasi Kelas II Tanjung Balai Karimun Tidak Berjalan dengan Efektif atau $\leq 70 \%$."

Dengan demikian efektivitas pelayanan pembuatan paspor dengan menggunakan Sistem Informasi Manajemen Keimigrasian (SIMKIM) terhadap kepuasan pelanggan di Kantor Imigrasi Kelas II Tanjung Balai Karimun adalah jumlah data yang terkumpul dibagi skor ideal yaitu $11.362: 15.000=0,7574$ atau $75,74 \%$ dari yang diharapkan. Efektivitas pelayanan pembuatan paspor dengan menggunakan Sistem Informasi Manajemen Keimigrasian (SIMKIM) Terhadap Kepuasan Pelanggan di Kantor Imigrasi Kelas II Tanjung Balai Karimun nilai yang dihipotesiskan adalah paling tinggi $70 \%$ dari nilai ideal.

Hipotesis statistiknya dapat dirumuskan sebagai berikut: Ho untuk memprediksi $\mu$ lebih

kecil atau sama dengan ( $\mathbf{5 7 0 \% )}$ ) dari skor ideal paling tinggi. Sedangkan Ha lebih besar dari

$70 \% \quad(>70 \%)$. Selanjutnya $t$ hitung dibandingkan dengan $t$ tabel dengan derajat kebebasan (df) $=n-k-1=150-1-1$ $=148$ dan taraf kesalahan $\infty=5 \% \mathrm{t}$ hitung lebih besar dari pada $t$ tabel atau $(1.918>1,97)$, maka Ha diterima dan Ho ditolak.

Berdasarkan hasil penelitian tentang pengujian hipotesis bahwa $\mathrm{Ha}$ diterima dan Ho ditolak. Dari data tersebut dijelaskan bahwa efektivitas pelayanan pembuatan paspor dengan menggunakan Sistem Informasi Manajemen Keimigrasian sudah mencapai angka $75,74 \%$, yang artinya dalam menjawab rumusan masalah yang telah diuraikan sebelumnya tentang seberapa besar efektivitas pelayanan pembuatan paspor dengan menggunakan (SIMKIM) terhadap kepuasan pelanggan di Kantor Imigrasi Kelas II Tanjung Balai Karimun sudah terjawab bahwa efektivitas pelayanan pembuatan paspor dengan menggunakan Sistem Informasi Manajemen Keimigrasian (SIMKIM) terhadap kepuasan pelanggan di Kantor Imigrasi Kelas II Tanjung Balai Karimun sudah mencapai angka $75,74 \%$ yang artinya sudah berjalan dengan efektif dan baik.

Secara keseluruhan pelayanan pembuatan paspor yang diberikan di Kantor Imigrasi Kelas II Tanjung Balai Karimun sudah termasuk kedalam kategori baik yaitu mencapai $75,74 \%$ dari angka minimal $70 \%$. Sebagaimana dari hasil penelitian bahwa keberhasilan pelayanan keimigrasian di Kantor Imigrasi Kelas II Tanjung Balai Karimun dalam memberikan pelayanan pembuatan paspor sudah berjalan dengan baik sesuai dengan aturan dan standar operasional prosedur (SOP) yang berlaku dengan penyebaran angket yang dilakukan peneliti dalam bentuk pernyataan dari berbagai sub indikator yang telah dipaparkan sebelumnya kepada masyarakat yang telah atau sedang melakukan pembuatan paspor.

Keberhasilan tersebut dipengaruhi karena pada saat ini Kantor Imigrasi Kelas II Tanjung Balai Karimun telah terbentuk suatu sistem yang terpadu dalam memberikan pelayanan kepada masyarakat. Dengan adanya sistem tersebut diharapkan dapat memberikan pelayanan secara cepat dan maksimal kepada pemohon jasa keimigrasian sesuai dengan janji layanan dari Imigrasi Kelas II Tanjung Balai Karimun itu sendiri yaitu memberikan kepastian persyaratan, kepastian biaya, kepastian waktu penyelesaian terhadap masyarakat pemohon jasa keimigrasian. Dibalik adanya sistem tersebut, yang masih 
menjadi perhatian adalah masih seringnya terjadi gangguan jaringan sehingga menyebabkan pelayanan menjadi terhambat prosesnya.

\section{KESIMPULAN}

Berdasarkan hasil penelitian yang diperoleh dari proses pengumpulan data dan analisis data yang telah dilakukan oleh peneliti dari aspek dimensi produktivitas yang memiliki tingkat persentase sebesar $70 \%$ dan masuk dalam kategori baik, dari hasil penelitian lapangan dan perhitungan menunjukkan Kantor Imigrasi Kelas II Tanjung Balai Karimun sudah mampu memenuhi kebutuhan masyarakat terhadap pelayanan keimigrasian. Dilihat dari aspek dimensi efisiensi dengan persentase $71 \%$ dan termasuk dalam kategori baik, hal ini menunjukkan Kantor Imigrasi Kelas II Tanjung Balai Karimun sudah memberikan pelayanan yang cepat dan banyak dalam satu harinya.

Dilihat dari aspek dimensi adaptasi dengan persentase $71 \%$ dan termasuk dalam kategori baik, hal ini menunjukkan bahwa Kantor Imigrasi Kelas II Tanjung Balai Karimun mampu menanggapi dan menyelesaikan masalah dalam proses pelayanan. Dilihat dari aspek dimensi pengembangan dengan persentase $70 \%$ dan termasuk dalam kategori baik, hal ini menunjukkan bahwa Kantor Imigrasi Kelas II Tanjung Balai Karimun selalu melakukan pembaharuan terhadap pengembangan sistem yang ada terhadap apa yang kurang optimal.

Dilihat dari aspek dimensi kepuasan dengan persentase $70 \%$ dan termasuk dalam kategori baik, hal ini menunjukkan bahwa Kantor Imigrasi Kelas II Tanjung Balai Karimun sudah memberikan pelayanan seperti yang diharapkan masyarakat. Dapat disimpulkan bahwa efektivitas pelayanan pembuatan paspor dengan menggunakan Sistem Informasi Manajemen Keimigrasian (SIMKIM) terhadap kepuasan pelanggan di Kantor Imigrasi Kelas II Tanjung Balai Karimun mencapai $75,74 \%$ dari angka yang dihipotesiskan yakni $70 \%$ yang berarti berjalan dengan baik. Hal ini menunjukkan bahwa hipotesis alternatif (Ha) diterima.

\section{DAFTAR PUSTAKA}

Keputusan Menteri Hukum dan HAM RI Nomor 19 tahun 2018 Tentang Organisasi dan Tata Kerja Kantor Imigrasi. www.imigrasi.go.id. Diakses tanggal 24 Juni 2019.

Peraturan Pemerintah Nomor 31 tahun 2013 Tentang Keimigrasian.www.imigrasi.go.id. Diakses tanggal 24 Juni 2019.

Riduwan, dkk. 2011. "Cara Mudah Belajar SPSS 17.0 Dan Aplikasi Statistik Penelitian". Bandung: CV. Alfabeta.

Sugiyono. 2014. "Metode Penelitian Kuantitatif, Kualitatif dan R\&D”. Bandung: CV Alfabeta.

Undang-Undang Nomor 6 tahun 2011 Tentang Keimigrasian. http://pih.kemlu.go.id. Diakses tanggal 24 Juni 2019. 